\title{
Lest We Forget About New Student Transitions
}

\author{
Bonita C. Jacobs
}

In the last seven months I have assumed a new position, sold a house, bought a house, moved 1,000 miles, graduated a daughter from high school, graduated a son from college, helped with his rather large wedding, moved a son in junior high to a new school, logged 40,000 frequent flyer miles in extended job interviews (four at UNT alone), learned to swim, learned to work with hundreds of new people, given over onehundred speeches and, unfortunately, lost my mother to an untimely death.

With the exception of losing my mom, all of the changes have been happy events. Unlike some of our new students, I've not received a D on a paper after making all A's in high school. I have not had to learn to live with someone with whom I may have little in common. I haven't had to question what I want to do with my life, and my values are firmly in place. Granted, being a new student is an exhilarating, exciting experience filled with hopes, butterflies, and adventure. Yet, even the most secure of students question themselves and their values, which is actually a positive developmental growth process. However, self doubt, disapproval from a peer or faculty member and learning to accept responsibility for poor decision-making is quite painful. Transition can be traumatic, and the inability of students to adjust to the transition negatively affects all our retention rates.

The lesson for me these last months has been to remember the transitions our new students face each semester. The short-term changes in my life have been insignificant compared to the single parent returning to school or to the eighteen-year-old leaving home for the first time. It is easy for us as "professionals" to overlook the basic tenets of transition strategies in planning glitzy orientation programs, award-winning first year courses, noteworthy learning communities, and cutting-edge programming ideas. The glitz, awards, noteworthiness, and cutting-edge ideas are terrific; we must have them to survive. However, the basics of human kindness and time to listen can make a difference in whether a student continues in school.

Perhaps it would be wise for us to heed the words of wisdom in the Senior Year Experience Series by Hartel, Schwartz, Blume, and Gardner (1994):

Today ... technological, demographic, and social changes occur with dizzying speed. Whereas once the only things that were certain were death and taxes, now we have to add "change" to the list. Therefore, in the workplace as in the rest of our lives, flexibility has become a virtue to be cultivated. (p. 77)

Whether we are faculty or staff, orientation directors or first year experience educators, students are our "workplace" and flexibility is our goal. The first year experience is

Bonita C. Jacobs, Ph. D., is Vice President for Student Development and Assistant Professor of Higher Education at the University of North Texas. 
about change, getting along with others, accepting differences, and finding a niche, and helping students succeed is about understanding transitions.

Hartel, W. C.; Schwartz, Stephen W.; Blume, Steven D.; \& Gardner, J. N. Ready for the Real World: Senior Year Experience Series. Belmont, CA: 1994. 